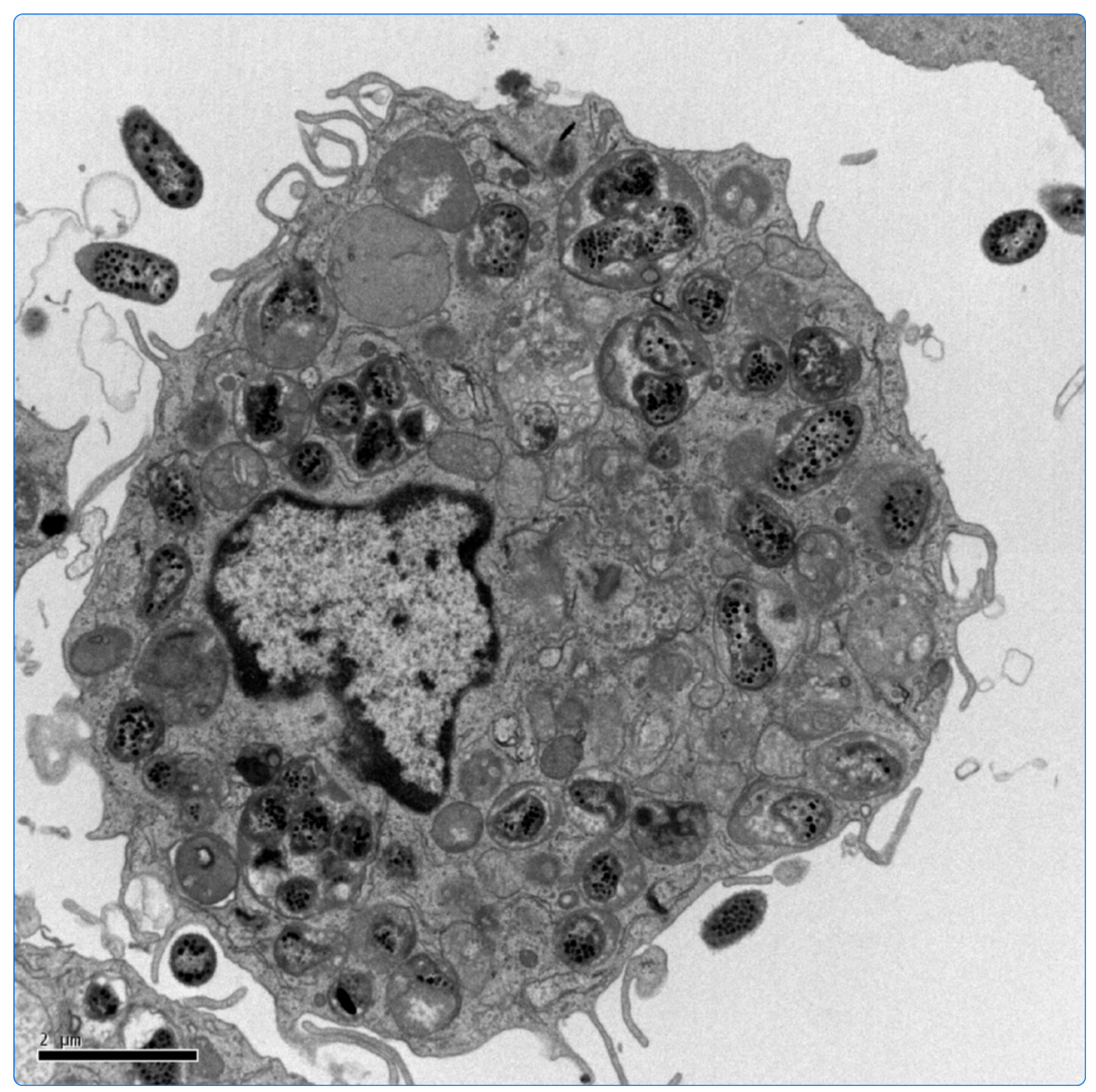

Differential interactions of virulent and non-virulent $H$. parasuis strains with naïve or swine influenza virus pre-infected dendritic cells

Mussá et al. 


\title{
Differential interactions of virulent and non-virulent $H$. parasuis strains with naïve or swine influenza virus pre-infected dendritic cells
}

\author{
Tufária Mussá ${ }^{1}$, Carolina Rodríguez-Cariño², Alejandro Sánchez-Chardi ${ }^{3}$, Massimiliano Baratelli ${ }^{1}$, Mar Costa-Hurtado ${ }^{1}$,
} Lorenzo Fraile ${ }^{4}$, Javier Domínguez ${ }^{5}$, Virginia Aragon ${ }^{1,6}$ and María Montoya ${ }^{1,6^{*}}$

\begin{abstract}
Pigs possess a microbiota in the upper respiratory tract that includes Haemophilus parasuis. Pigs are also considered the reservoir of influenza viruses and infection with this virus commonly results in increased impact of bacterial infections, including those by H. parasuis. However, the mechanisms involved in host innate responses towards H. parasuis and their implications in a co-infection with influenza virus are unknown. Therefore, the ability of a non-virulent H. parasuis serovar 3 (SW114) and a virulent serovar 5 (Nagasaki) strains to interact with porcine bone marrow dendritic cells (poBMDC) and their modulation in a co-infection with swine influenza virus (SwIV) H3N2 was examined. At 1 hour post infection (hpi), SW114 interaction with poBMDC was higher than that of Nagasaki, while at $8 \mathrm{hpi}$ both strains showed similar levels of interaction. The co-infection with H3N2 SwIV and either SW114 or Nagasaki induced higher levels of IL-1 $\beta$, TNF- $a, I L-6, I L-12$ and IL-10 compared to mock or H3N2 SwIV infection alone. Moreover, IL-12 and IFN-a secretion differentially increased in cells co-infected with H3N2 SWIV and Nagasaki. These results pave the way for understanding the differences in the interaction of non-virulent and virulent strains of $H$. parasuis with the swine immune system and their modulation in a viral co-infection.
\end{abstract}

\section{Introduction}

Haemophilus parasuis is a non-motile, Gram-negative, small pleomorphic rod of the family Pasteurellaceae [1] and the causal agent of Glässer's disease, which is characterized by fibrinous polyserositis and polyarthritis [2,3]. Glässer's disease is common in all countries with commercial pig production and its economic cost is considered one of the highest in nursery pigs, in which the disease is more prevalent [4]. Fifteen serovars of $H$. parasuis have been defined, with serovars $1,5,10,12$, 13 and 14 classified as highly virulent; serovars 2,4 and 15 as moderately virulent; and serovars $3,6,7,8,9$ and 11 as non-virulent [5]. The pathogenesis of $H$. parasuis remains unclear, but disease production is influenced by stress, the presence of virulent strains of $H$. parasuis and other pathogens in the farm and immune status of the animals [6]. Differences between virulent and non-

\footnotetext{
* Correspondence: maria.montoya@cresa.uab.es

${ }^{1}$ Centre de Recerca en Sanitat Animal (CReSA), UAB-IRTA, Campus de la Universitat Autònoma de Barcelona (UAB), 08193 Bellaterra, Barcelona, Spain ${ }^{6}$ Institut de Recerca i Tecnologia Agroalimentaria (IRTA), Barcelona, Spain Full list of author information is available at the end of the article
}

virulent strains have been determined at the genetic level [7], in functional assays of phagocytosis [8], serum resistance [9], adhesion and invasion of endothelial cells $[10,11]$ and, more recently, in adhesion and invasion to epithelial cells [12]. However, $H$. parasuis interaction with porcine DC has not been addressed before, neither has its possible immunomodulation in the presence of other respiratory pathogens such as swine influenza virus (SwIV).

Influenza viruses are enveloped, single stranded RNA (ssRNA) viruses in the Orthomyxoviridae family. Pigs play a crucial role in the interspecies transmission of influenza viruses [13-15]. The pathogenicity of influenza virus lies in its ability to elude host anti-viral immune responses. In pigs, primary SwIV infection induced cytokines like IFN- $\alpha$, IL-6, IL-1, TNF- $\alpha$, IFN- $\gamma$ and IL-12, which have been associated with acute influenza virus infection in pigs [16].

An efficient immune response against a particular pathogen depends on the efficient recognition of the pathogen/ antigen, and dendritic cells (DC) play an essential role in 
priming this effective immune response. They constitute the bridge between the innate and adaptive immune response [17]. According to their functionality and phenotype, DC can be classified as conventional DC (cDC) known as professional presenting cells or plasmacytoid DC (pDC), which naturally produce high levels of type-I interferon [18]. In swine, both $\mathrm{cDC}$ and $\mathrm{pDC}$ have important antigen-presenting functions and they complement each other by having distinct regulation of major histocompatibility complex class I (MHC-I, SLA-I in swine) and class II (MHC-II, SLA-II in swine) depending on antigen presentation and different profile of secreted cytokines [19]. Interestingly, conventional DC are amongst the first cells encountered by most viruses, simply due to their availability at every possible entry site of the body [20]. Respiratory disease in pigs is common in modern pig production worldwide and is often referred to as porcine respiratory disease complex. This disease complex results from infection with various combinations of primary and secondary respiratory pathogens, including $H$. parasuis and SwIV [21,22]. Our main goal was to assess whether $H$. parasuis virulence implied a differential interaction with swine DC and whether this interaction would be altered in the presence of another respiratory pathogen involved in the porcine respiratory disease complex, such as SwIV, considering all this previous knowledge and the availability of DC beneath the epithelium of respiratory organs. Here, we report different patterns of interaction and activation of swine DC after encountering virulent and non-virulent $H$. parasuis strains which was in turn altered in the presence of swine influenza virus. These results will help understanding how bacteria-viral infection influences the outcome of the elicited immune response.

\section{Material and methods}

\section{Porcine bone marrow dendritic cells (poBMDC)}

Bone marrow hematopoietic cells were obtained from femurs of eight-week old healthy Large white X Landrace pigs, negative for porcine reproductive and respiratory syndrome virus (PRRSV) and type-2 porcine circovirus (PCV2) by RT-PCR as previously described by Olvera et al. and Sibila et al. [23,24]. These animals were also negative by enzyme linked-immunosorbent assay (ELISA) for influenza virus and Actinobacillus pleuropneumoniae (HIPRA, Amer, Spain), for Mycoplasma (OXOID, Cambridge, UK), for Parvovirus, Adenovirus and Aujeszky's disease virus (INGENASA, Madrid, Spain), and Salmonella (SVANOVA Biotech AB, Uppsala, Sweden). Bone marrow dendritic cells (BMDC) were generated using an eight day protocol as previously described by Mussá et al. and Carrasco et al. [25,26]. Briefly, bone marrow haematopoietic cells (BMHC) were resuspended in RPMI-1640 (Lonza, Walkesville, USA) culture medium containing $2 \mathrm{mM}$ of L-glutamine (Invitrogen ${ }^{\circledR}$, Barcelona,
Spain), $100 \mathrm{U} / \mathrm{mL}$ of Polymixin B (Sigma-Aldrich, Madrid, Spain) $10 \%$ of fetal calf serum (FCS) Euroclone, Sziano, Italy) and $100 \mathrm{U} / \mathrm{mL}$ of penicillin with $100 \mu \mathrm{g} / \mathrm{mL}$ of streptomycin (Invitrogen ${ }^{\circledR}$, Barcelona, Spain). Every 3 days new medium containing $100 \mathrm{ng} / \mathrm{mL}$ of rpGM-CSF (R\&D Systems, Madrid, Spain) was added. At day 8 of generation floating and semi-adherent cells were harvested, washed in RPMI with L-glutamine only and used in the proposed experiments. Animal care and procedures were in accordance with the guidelines of the Good Laboratory Practices (GLP) under the supervision of the Ethical and Animal Welfare Committee of the Universitat Autònoma de Barcelona (number of approval: 1189) and under the supervision of the Ethical and Animal Welfare Committee of the Government of Catalonia (number of approval: 5796).

\section{Haemophilus parasuis}

Two reference strains of $H$. parasuis, SW114 and Nagasaki, belonging to the nasal and systemic clade respectively on the multilocus sequence typing (MLST) were used to inoculate poBMDC. SW114 is the serovar 3 reference strain (non-virulent); Nagasaki is the serovar 5 reference strain (highly virulent) $[5,27]$. For DC inoculation, bacteria were grown overnight as described by Olvera et al. [8]. Briefly, strains were cultured on chocolate agar plates (BioMérieux, Madrid, Spain) overnight at $37^{\circ} \mathrm{C}$ and $5 \%$ $\mathrm{CO}_{2}$. The following day, colonies were collected and resuspended in PBS at the appropriate concentration. Bacterial counts in the inocula were confirmed by plating serial dilutions on chocolate agar plates.

\section{Influenza virus}

Porcine A/swine/Spain/SF32071/2007(H3N2) SwIV strain was isolated from a natural outbreak in a conventional farm in 2007, in Spain. Eight sequences of this virus, corresponding to HA, NP, PA, PB2, NA, PB1/ PB1F2, NS1/NS2 and M1/M2 genes were submitted to GenBank (accession numbers: HE774666, HE774667, HE774668, HE774669, HE774670, HE774671, HE774672 and HE774673). Virus isolation and SwIV-cell infection were performed as previously described by Mussá et al. [26] except for the fact that the post infection medium did not contain any antibiotics.

\section{DC infection or stimulation with Poly:IC}

After 8 days of generation, poBMDC were harvested and washed with RPMI with neither antibiotic nor serum, counted and plated on 24 well plates (Figure 1a and 1b). Then, $10^{7}$ CFU (MOI 10) of SW114 or Nagasaki were added to the wells. After $1 \mathrm{~h}$ of incubation at $37^{\circ} \mathrm{C}$ with the bacteria, cells were washed thrice with RPMI by centrifugation at $450 \times g$ for $5 \mathrm{~min}$. After the third wash the supernatants were discarded, $500 \mu \mathrm{L}$ of RPMI containing 


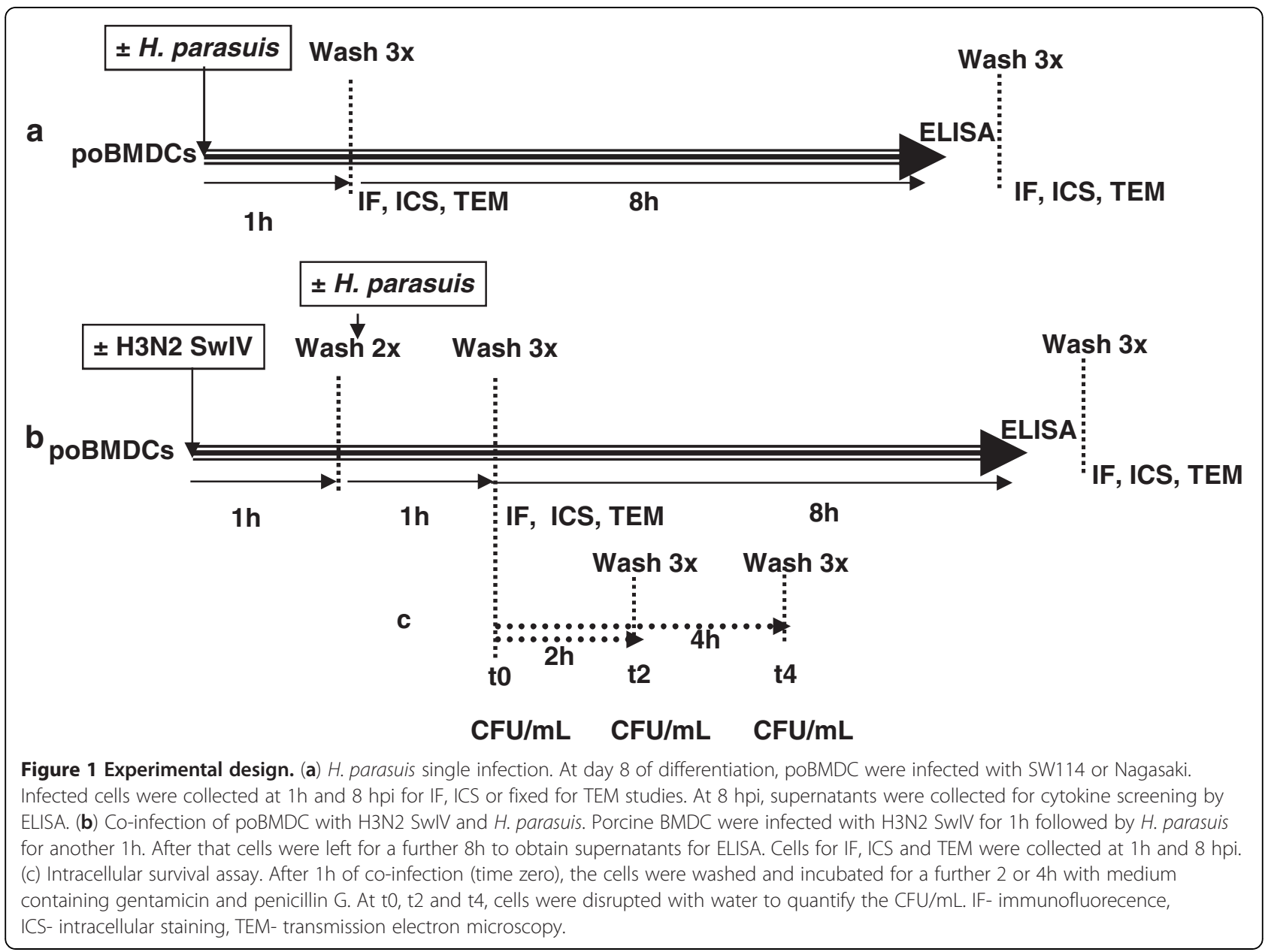

L-glutamine and $10 \%$ FCS were added and plates were incubated for further different times at $37^{\circ} \mathrm{C} 5 \% \mathrm{CO}_{2}$. While at 1 hpi with bacteria, cells were washed, harvested and stained, at $8 \mathrm{hpi}$ and the supernatants were frozen at $-20^{\circ} \mathrm{C}$ for cytokine detection by ELISA (see below) and the cells were harvested for staining. When required, infection with H3N2 SwIV was performed as follows: one hundred microliters with $10^{4} \mathrm{TCID}_{50}$ of swine influenza $\mathrm{H} 3 \mathrm{~N} 2$ virus were added and left to adhere for $1 \mathrm{~h}$ at $37^{\circ} \mathrm{C} 5 \% \mathrm{CO}_{2}$. After that, cells were washed once with RPMI and incubated with medium only or with $H$. parasuis as stated previously. To analyse the effect of toll like receptor 3 (TLR3) in $H$. parasuis infection, the cells were stimulated with $50 \mu \mathrm{g} / \mathrm{mL}$ of Polyinosinic:Polycytidilic acid salt (Poly: IC) (SigmaAldrich, Madrid, Spain) for $4 \mathrm{~h}$ before infection with $H$. parasuis and then left for a further $5 \mathrm{~h}$.

\section{Staining of $H$. parasuis}

$H$. parasuis was assessed by flow cytometry or by immunofluorescence at $1 \mathrm{~h}$ and at $8 \mathrm{hpi}$ (Figure 1a and $1 \mathrm{~b}$ ). For flow cytometry, poBMDC were fixed with $4 \%$ paraformaldehyde (EMS, Hatfield, PA, USA) for $10 \mathrm{~min}$ at room temperature (RT). After washing (centrifugation $450 \times g$ for $5 \mathrm{~min}$ at $4^{\circ} \mathrm{C}$ ), cells were permeabilized with $0.1 \%$ Triton-X100 in PBS for $15 \mathrm{~min}$ at $37^{\circ} \mathrm{C}$. Then, $1 \mathrm{~h}$ incubation at $4^{\circ} \mathrm{C}$ for each antibody was used. A polyclonal rabbit anti-SW114 or anti-Nagasaki serum $(10 \mu \mathrm{L}$ serum/ $490 \mu \mathrm{L}$ PBS $2 \%$ FCS) was used as primary antibody. An FITC-conjugated monoclonal anti-rabbit (Clone RG-16, Sigma-Aldrich, Madrid, Spain) was used as a secondary antibody at 1:100 dilution. For immunofluorescence, the cells were infected on a circular glass cover slip (VWR International, Barcelona, Spain) inserted in 24 well plates (Nunc $^{\circledR}$, Kamstrupvej, Denmark). After infection, supernatants were collected for ELISA. Then, the cells were fixed with ethanol (Panreac, Barcelona, Spain) for $10 \mathrm{~min}$ at $4^{\circ} \mathrm{C}$, dehydrated with acetone and then permeabilized with $0.1 \%$ Triton $\mathrm{X}-100$ for $15 \mathrm{~min}$ at $37^{\circ} \mathrm{C}$. Then, the cells were washed with PBS with $0.1 \%$ BSA and $100 \mu \mathrm{L}$ of polyclonal rabbit anti-SW114 or anti-Nagasaki serum diluted as before were added and the slides were incubated for $1 \mathrm{~h}$ at $4^{\circ} \mathrm{C}$. After three washes, a secondary antibody antirabbit Immunoglobulin-FITC diluted 1:50 was added and 
incubated for $1 \mathrm{~h}$ at $4^{\circ} \mathrm{C}$. Phalloidin, Tetramethylrhodamine B isothiocyanate (TRITC) (Sigma-Aldrich, Madrid, Spain) at $5 \mu \mathrm{g} / \mathrm{mL}$ was used to stain actin filaments situated beneath the cell membrane and finally after several washes, nuclei were counterstained with DAPI. Cover slips were dried and mounted using 1 drop of Fluoprep (BioMérieux, Madrid, Spain). To detect autofluorescence, mock or infected-poBMDC were stained as controls with the primary and/or secondary antibody. Treated cells were viewed on a Nikon eclipse 90i epifluorescence microscope equipped with a DXM 1200F camera (Nikon Corporate, Japan). To assess the association of bacteria with poBMDC, image stacks were captured using a Leica TCS SP2 confocal microscope, with an objective of $63 \times . Z$ stack images were acquired at intervals of $0.3 \mu \mathrm{m}$. Images were processed by using the Image $\mathrm{v} 1.42 \mathrm{k}$ software [28].

\section{Transmission electron microscopy (TEM)}

Mock and infected poBMDC were fixed with $2 \%(\mathrm{w} / \mathrm{v})$ paraformaldehyde (EMS, Hatfield, PA, USA) and 2.5\% (v/v) glutaraldehyde (EM grade, Merck, Darmstadt, Germany) in $0.1 \mathrm{M}$ phosphate buffer (PB, SigmaAldrich, Steinheim, Germany), pH 7.4 and processed following conventional procedures as previously described in detail by Rodriguez-Cariño et al., [29]. Briefly, the samples were post-fixed with osmium, dehydrated in acetone, embedded in Epon, polymerized at $60^{\circ} \mathrm{C}$ and cut with an ultramicrotome. Finally, ultrathin sections placed in copper grids were contrasted with conventional uranyl acetate and Reynolds lead citrate solutions and observed using a Jeol 1400 (Jeol LTD, Tokyo, Japan) transmission electron microscope equipped with a CCD GATAN ES1000W Erlangshen camera.

\section{Intracellular survival assay}

Cells were infected as described above. After $1 \mathrm{~h}$ of $H$. parasuis infection (time zero) (Figure $1 \mathrm{~b}$ and 1c), RPMI containing $2 \mathrm{mM}$ of L-glutamine and $10 \%$ of FCS, penicillin $\mathrm{G}(5 \mu \mathrm{g} / \mathrm{mL})$ and gentamicin $(100 \mu \mathrm{g} / \mathrm{mL})$ (both from Sigma-Aldrich, Madrid, Spain) was added and the poBMDC were left at $37^{\circ} \mathrm{C}$ and $5 \% \mathrm{CO}_{2}$ for a further two or four hours. At these times, after three washes with PBS, poBMDC were disrupted using sterile water, and serial 10 fold dilutions of lysate were plated on chocolate agar and incubated for $48 \mathrm{~h}$. At the same times, $100 \mu \mathrm{L}$ of cell culture supernatants were plated on chocolate agar (Biomérieux, Madrid, Spain) to check if $H$. parasuis was efficiently killed by the antibiotics.

\section{Activation markers}

Fifty microliters of poBMDC $\left(5 \times 10^{5}\right.$ cells $)$ were plated in 96 well U-bottom plates (Nunc ${ }^{\circledR}$ Kamstrupvej, Denmark) and washed with PBS $2 \%$ FCS. Then, $100 \mu \mathrm{L}$ hybridoma supernatants containing anti-SLA-I (4B7/8) or anti-SLA-II (1F12), and the human CTLA4 murine immunoglobulin fusion protein (CTLA4-muIg; Ancell, Bayport, Minnesota, USA) were used as primary antibodies. The secondary antibody was R-phycoerythrin anti-mouse IgG (Jackson ImmunoResearch, Suffolk, UK). Stained cells were acquired using a Coulter ${ }^{\circledR}$ EPICS XL-MCL cytometer and analysed with the EXPO 32 ADC v.1.2 program. The mean fluorescence intensities (MFI) of each sample were analysed.

\section{Enzyme linked-immunosorbent assay (ELISA)}

The supernatants of $8 \mathrm{~h}$ infected-poBMDC were thawed only once for cytokine detection by ELISA. All ELISA were read with KC Junior Program (BioTek, Potton, UK) using the filter PowerWave XS reader. For IL-6, IL-1 $\beta$, IL10 and TNF- $\alpha$, the Duo Set Developed ELISA system from $R \& D$ System ${ }^{\circledR}$ was used following the manufacturer's instructions while for IFN- $\alpha$ an in house ELISA using antibodies purchased from PBL Interferon Source was used according to Kekarainen et al. [30]. To detect IL-8 and IL18, swine IL-8 (CXCL8) VetSet ${ }^{\mathrm{TM}}$ ELISA development kit (Kingfisher Biotek, Saint Paul, MN, USA) and pig IL-18 Module Set BMS672MST (Bender Med Systems, Vienna, Austria) were used following the manufacturer's instructions. Finally IL-12 secretion was analysed using antibodies anti IL-12/IL-23p40 (R\&D Systems, Madrid, Spain) according to the manufacturer's instructions with the following amounts of antibodies: $2 \mu \mathrm{g} / \mathrm{mL}$ of anti IL-12/IL23 monoclonal antibody were used to coat a 96 well plate (Costar, NY, USA) overnight at RT. After washing, serial dilutions of the recombinant porcine IL-12 starting from $10000 \mathrm{pg} / \mathrm{mL}$ were added. Then $125 \mathrm{ng} / \mathrm{mL}$ of biotinylated anti-porcine IL-12/IL-23 p40 antibody was used. Finally, $0.05 \mu \mathrm{g} / \mathrm{mL}$ of peroxidase-conjugated streptavidin (Jackson ImmunoResearch, Suffolk, UK) was added. The reaction was revealed using 3,3,5,5' tetramethylbenzidine

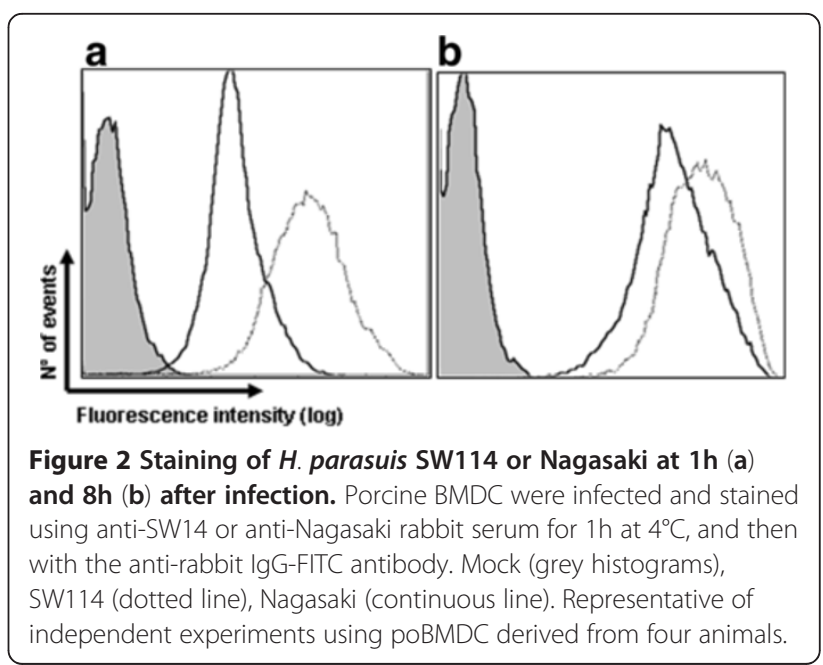


(TMB) (Sigma-Aldrich, Madrid, Spain) and stopped using $\mathrm{H}_{2} \mathrm{SO}_{4}(0.5 \mathrm{M})$. The limits of detection were $3.9 \mathrm{U} / \mathrm{mL}$ and $78.1 \mathrm{pg} / \mathrm{mL}$ for IFN- $\alpha$ and IL-12 respectively.

\section{Statistical analysis}

All statistical analyses were performed using SPSS 15.0 software (SPSS Inc., Chicago, IL, USA). For statistical comparisons, the pig (as source of cells) was used as the experimental unit. The significance level $(\alpha)$ was set at 0.05 . A non-parametric test (Mann-Whitney) was chosen to compare the different values obtained for all the immunological parameters between groups at all sampling times.

\section{Results}

Differential interaction of $H$. parasuis Nagasaki and SW114 individually or in SwIV co-infection with swine DC Measuring $H$. parasuis interaction with swine DC may be a suitable indicator of virulence since DC ability to capture antigens is important to elicit a specific immune response. At 1 hpi poBMDC infected with SW114 or Nagasaki showed higher fluorescence intensity compared to mock cells (Figure 2a), however, at $8 \mathrm{hpi}$ it seems that both strains interacted equally with poBMDC compared to the mock cells (Figure $2 b$ ).

The ability of poBMDC to interact with and internalise $H$. parasuis was confirmed by confocal and electron microscopy. Confocal microscopy was performed using serum against each particular strain. One hour after infection, the SW114 strain was observed attached and inside poBMDC (Figure 3a and $3 \mathrm{~b})$ and at $8 \mathrm{hpi}$ bacterial numbers increased inside the cell (Figure $3 \mathrm{c}$ and $3 \mathrm{~d}-\mathrm{f}$ ). Conversely, the Nagasaki strain was mostly attached to the cells 1 hpi, apparently in fewer numbers (Figure 4a). At 8 hpi, Nagasaki was observed not only attached but also inside the DC (Figure $4 \mathrm{~b}$ and $4 \mathrm{c}-\mathrm{g}$ ).

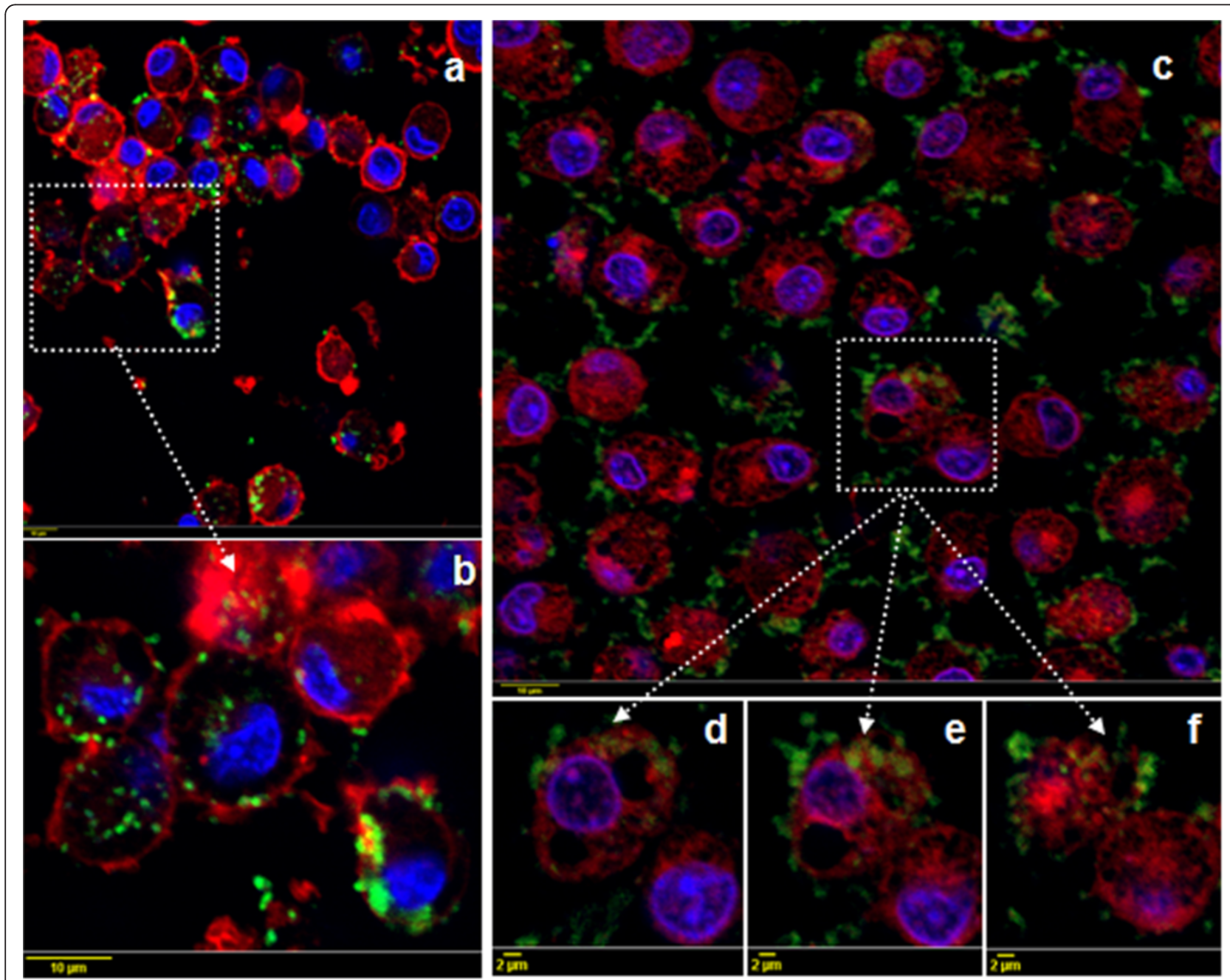

Figure 3 Confocal images of poBMDC infected with SW1 14 for $\mathbf{1 h}(\mathbf{a}-\mathbf{b})$ and $\mathbf{8 h}(\mathbf{c}-\mathbf{f})$. Porcine BMDC were stained with polyclonal antiSW14 rabbit serum and anti-rabbit IgG-FITC antibody. Cytoplasm was stained with rhodamine-phalloidin and nuclei with DAPI. Green (SW114), red (cytoplasm), blue (nuclei). Bars a,b and $c=10 \mu \mathrm{m}$, while bars $\mathrm{d}-\mathrm{f}=2 \mu \mathrm{m}$. $\mathrm{b}$ and $\mathrm{d}-\mathrm{f}$ are representative results of $\mathrm{Z}$ stack sections. 


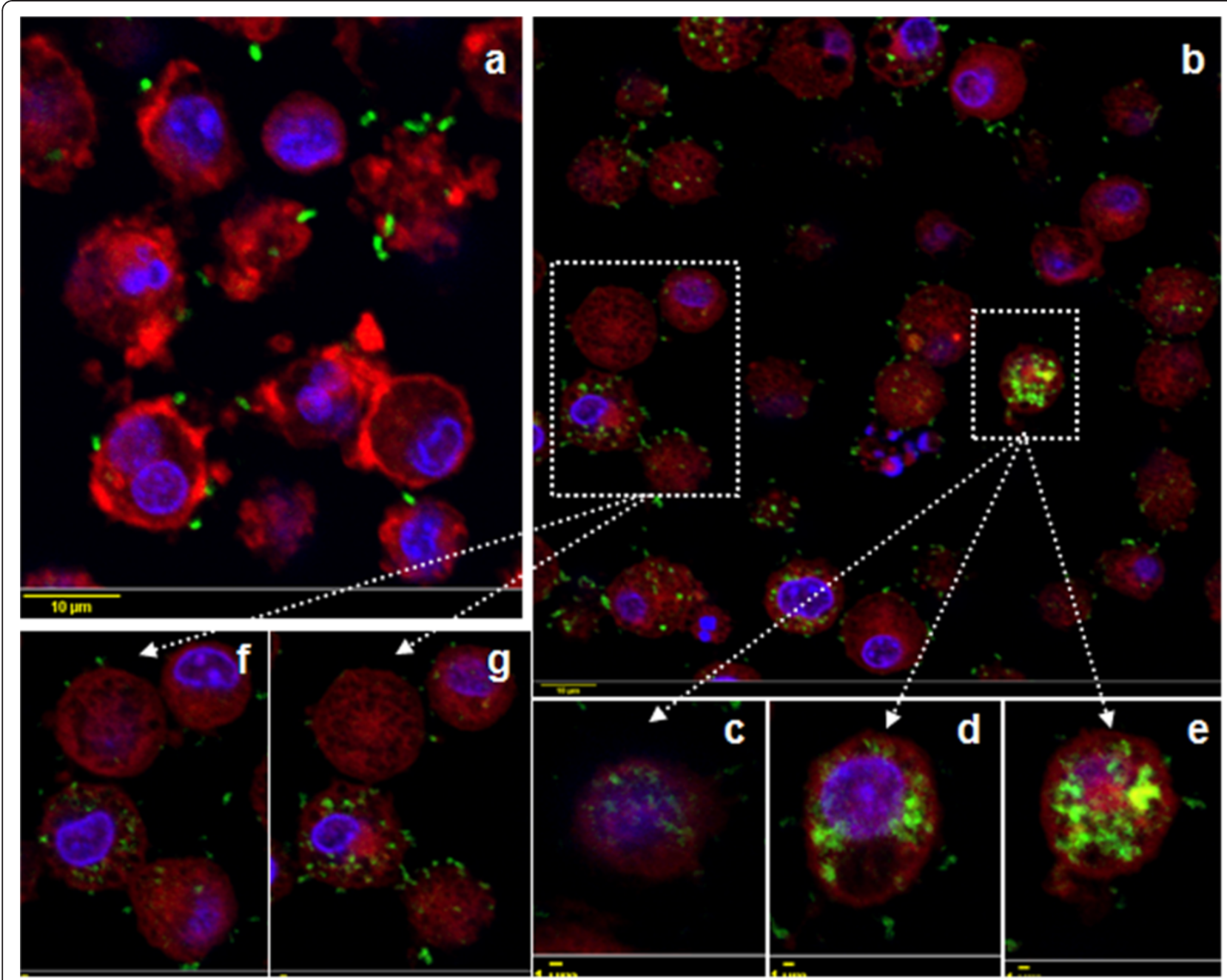

Figure 4 Confocal images of poBMDC infected with Nagasaki for $\mathbf{1 h}(\mathbf{a})$ and $\mathbf{8 h}(\mathbf{b}-\mathbf{g})$. Porcine BMDC were stained with polyclonal antiNagasaki rabbit serum and anti-rabbit IgG-FITC antibody. Cytoplasm was stained with rhodamine-phalloidin and nuclei with DAPI. Green (Nagasaki), red (cytoplasm), blue (nuclei). Bars $a$ and $b=10 \mu \mathrm{m}$, while bars $\mathrm{c}-\mathrm{g}=1 \mu \mathrm{m}$. $\mathrm{c}-\mathrm{g}$ are representative results of $\mathrm{Z}$ stack sections.

The interaction of the two strains with poBMDC was also analysed at the ultrastructural level by electron microscopy. At 1 or $8 \mathrm{hpi}$, mock poBMDC showed normal morphology (Figure 5a and $5 \mathrm{~d}$ ). In agreement with the fluorescence microscopy results, differential interaction with poBMDC was observed after SW114 or Nagasaki infection: at $1 \mathrm{hpi}$, higher numbers of SW114 bacteria were found inside phagolysosome-like structures as compared with Nagasaki infected cells (Figure 5b). At 8 hpi, more than one SW114 bacteria were found inside phagolysosome-like structures (Figure 5e). Infection of poBMDC with Nagasaki induced more apparent subcellular changes. Although, few bacteria were observed inside the poBMDC after the first hpi, an important number of vesicles were observed (Figure 5c). These changes were more evident at $8 \mathrm{hpi}$. At this time, larger vesicles containing more than one Nagasaki bacteria were observed (Figure 5f).
To get insight into the changes in the interaction of DC with $H$. parasuis as a consequence of a previous infection by SwIV, in vitro co-infection experiments were performed. The behaviour of poBMDC to $H$. parasuis infection when a previous infection with H3N2 SwIV took place was analysed by flow cytometry (Additional file 1: Figure S1), fluorescence microscopy (Additional file 2: Figure S2) and TEM (Figure 6). As previously observed, both $H$. parasuis strains showed differences in their interaction with poBMDC in the same range, even when SwIV pre-infection was present: H3N2 SwIV infected DC exhibited a higher level of interaction with SW114 than the Nagasaki co-infected cells at $1 \mathrm{hpi}$ (Additional file 1: Figure S1) and at 8 hpi (Figure 6a-b and $6 \mathrm{~d}-\mathrm{e})$. In these experiments, co-infected poBMDC presented SwIV virus-like particles inside vesicles. On some occasions SW114 or Nagasaki were in the same phagolysosome-like structures as these SwIV virus-like 


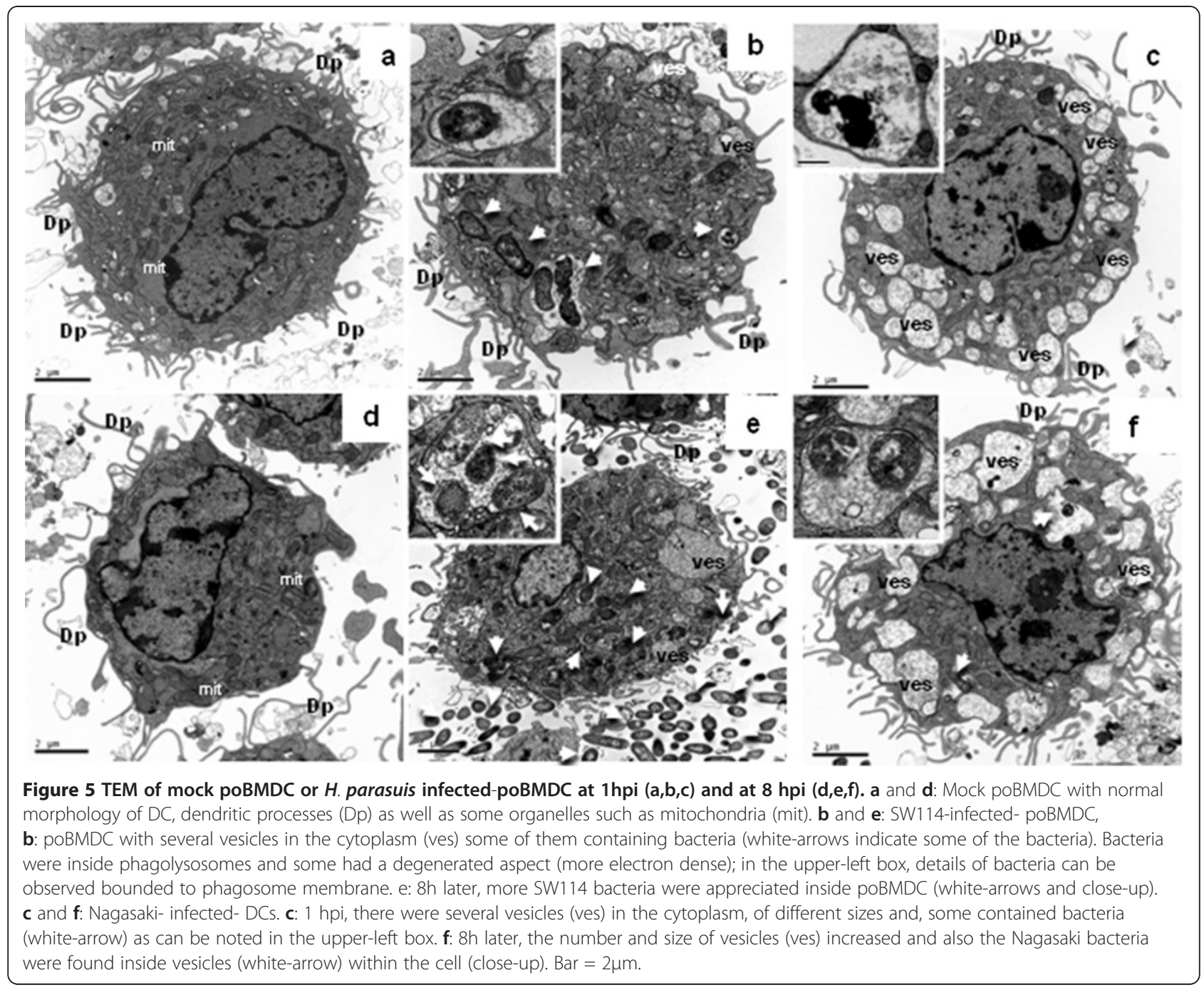

particles (Figure 6c and 6f). At 8 hpi, SW114 co-infected cells showed many bacteria inside phagolysosome-like structures which might define different levels of degradation (Additional file 3: Figure S3d-g). Moreover, the organelles of Nagasaki co-infected cells showed important changes such as dilation of the Golgi complex (Additional file 4: Figure S4f, S4i) and degraded bacteria inside phagolysosome-like structures (Additional file 4: Figure S4h).

\section{Intracellular survival of $H$. parasuis in poBMDC}

The above-mentioned results suggest that bacterial numbers differed for both $H$. parasuis strains in DC. To analyze the intracellular fate of bacteria once internalized, we quantified bacterial intracellular survival over time. Precisely, after $60 \mathrm{~min}$ incubation of $H$. parasuis with DC to get optimal internalisation, antibiotics were added and the treatment was lengthened for different times up to $4 \mathrm{~h}$ (Figure 1c). Before antibiotic addition, mean values of SW114 viable bacteria were $3.8 \times 10^{6}$
$\mathrm{CFU} / \mathrm{mL}$ while for Nagasaki they were $1.1 \times 10^{6} \mathrm{CFU} /$ $\mathrm{mL}$. As shown in Figure 7, once internalised, the number of viable bacteria significantly decreased at time $2 \mathrm{~h}$ and $4 \mathrm{~h}(0.03>p<0.04)$ when compared to time zero in all tested groups (Figure 7). Differences between SW114 and Nagasaki in their interaction with poBMDC were noteworthy, with the number of SW114 being significantly higher than the number of Nagasaki.

\section{Activation profile of $H$. parasuis-SwIV-infected DC}

One of the hallmarks of DC is the triggering of an effective immune response by capture, processing and presentation of antigens to $\mathrm{T}$ cells. The antigen presenting process needs a complete signalling, where MHC presenting molecules (signal one), activation or costimulatory (signal two) and soluble mediators such as cytokines (signal three) participate. Therefore, to evaluate the level of expression of activation markers, poBMDC were stained for SLA-I, SLA-II and CD80/86 after infection with SW114 or Nagasaki. After 1h of infection with 


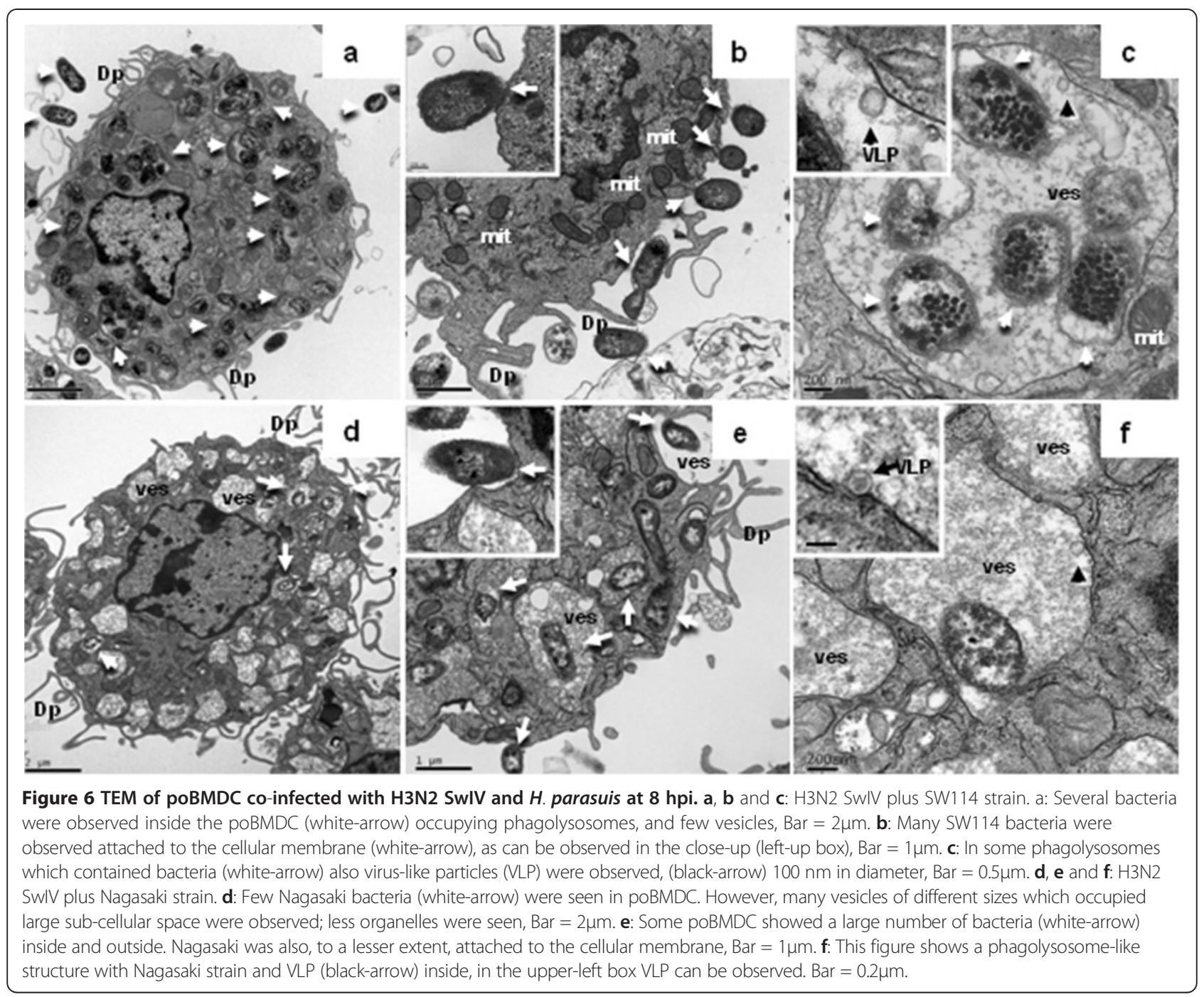

$H$. parasuis, no significant differences in SLA-I, SLAII or CD80/86 expression were found with any $H$. parasuis strains (Figure 8). Statistically significant decreases $(p<0.05)$ were found at $8 \mathrm{hpi}$ in SLA-I and SLA-II of SW114-infected poBMDC compared to SwIV infected cells or mock respectively (Figure $8 \mathrm{a}$ and $8 \mathrm{~b}$ ). No significant differences were observed in CD80/86 expression (Figure 8c).

Expression levels of activation markers were also analysed after co-infection. One hour after H3N2 SwIV single infection or H3N2 SwIV-SW114 and H3N2 SwIVNagasaki co-infections, no significant differences $(p>0.05)$ were observed in SLA-I and CD80/86 expression. However, at this time, significant decreases $(p<0.05)$ of SLA-II were observed in H3N2 SwIV plus SW114 or Nagasaki co-infected cells (Figure 8b). At 8 hpi, only H3N2 SwIV single infection or co-infection with Nagasaki induced a statistically significant increase of SLA-I when compared to SW114 single infection (Figure 8a).

\section{Cytokine pattern of $H$. parasuis infected DC: effects of} SwIV co-infection

Once the profile of poBMDC activation after $H$. parasuis infection was characterised, we analysed the cytokine profile to determine the type of immune response that these pathogens may induce in poBMDC. Consequently, IL-1 $\beta$, TNF- $\alpha$, IL-6, IL-10, IL-8, IL-12, IL-18 and IFN- $\alpha$ were analysed at $8 \mathrm{hpi}$. Statistically significant differences $(p<0.05)$ were found in the secretion of IL-1 $\beta$, IL-6, TNF- $\alpha$ and IL-10 between SW114 and Nagasakiinfected poBMDC compared to mock cells. IL-12 was secreted in higher levels by SW114-infected cells compared to Nagasaki-infected cells and to mock cells (Figure 9). No significant differences were found in IL-8, IL-18 or IFN- $\alpha$ secretion from SW114 or Nagasaki infected cells compared to the mock controls (Figure 9e, 9f and 9h).

Co-infection of poBMDC with H3N2 SwIV and SW114 or Nagasaki resulted in similar levels in most of the tested 


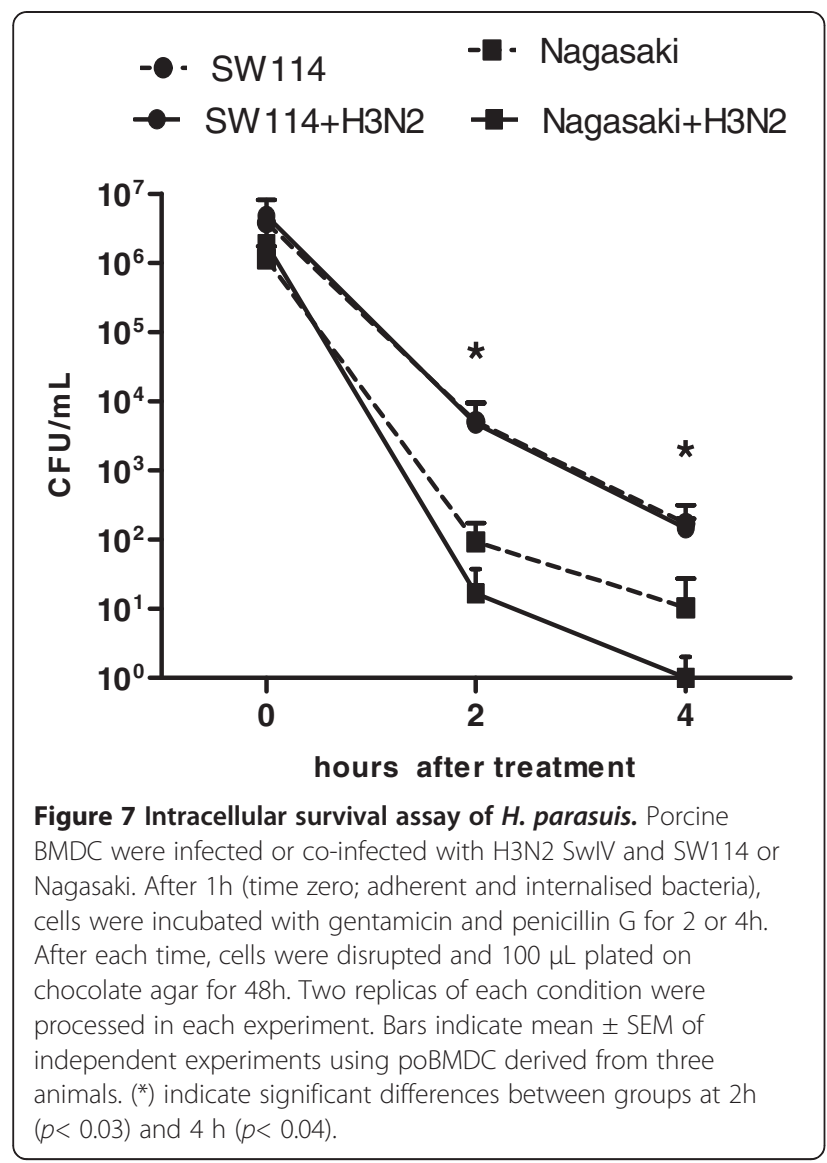

cytokines. However, a significant increase in the secretion of IL-12 compared to mock control cells was observed at 8 hpi in Nagasaki co-infected cells $(p<0.05)$ (Figure 9d). IL-12 production in Nagasaki infected-poBMDC was modulated by a previous H3N2 SwIV virus infection, while induction of IL-12 by SW114 was not affected. H3N2 SwIV induced higher levels of IFN- $\alpha$ compared to mock control cells. Surprisingly, a significant decrease of this cytokine was observed in H3N2 SwIV-SW114 co-infected cells compared to H3N2 SwIV infected cells whereas the Nagasaki strain significantly upregulated IFN- $\alpha$ secretion in co-infected cells compared to Nagasaki single infected cells (Figure 9h).

\section{Poly:IC immunomodulation on $H$. parasuis infected DC}

The differences in IL-12 and IFN- $\alpha$ secretion by cells infected with SW114 or Nagasaki strains and the modulation of both cytokines in SwIV-H. parasuis co-infected DC led us to investigate whether other stimuli, like Poly I: $\mathrm{C}$ as a surrogate of an RNA viral infection, could alter this cytokine pattern in the same way. Hence, DC were pretreated for 4h. with Poly:IC, before infection with $H$. parasuis. Lower levels of IL-12 and IFN- $\alpha$ induced by Nagasaki infection, shown in Figure 9, were overcome by pre-treatment with Poly:IC, levelling up IFN- $\alpha$ in Nagasaki

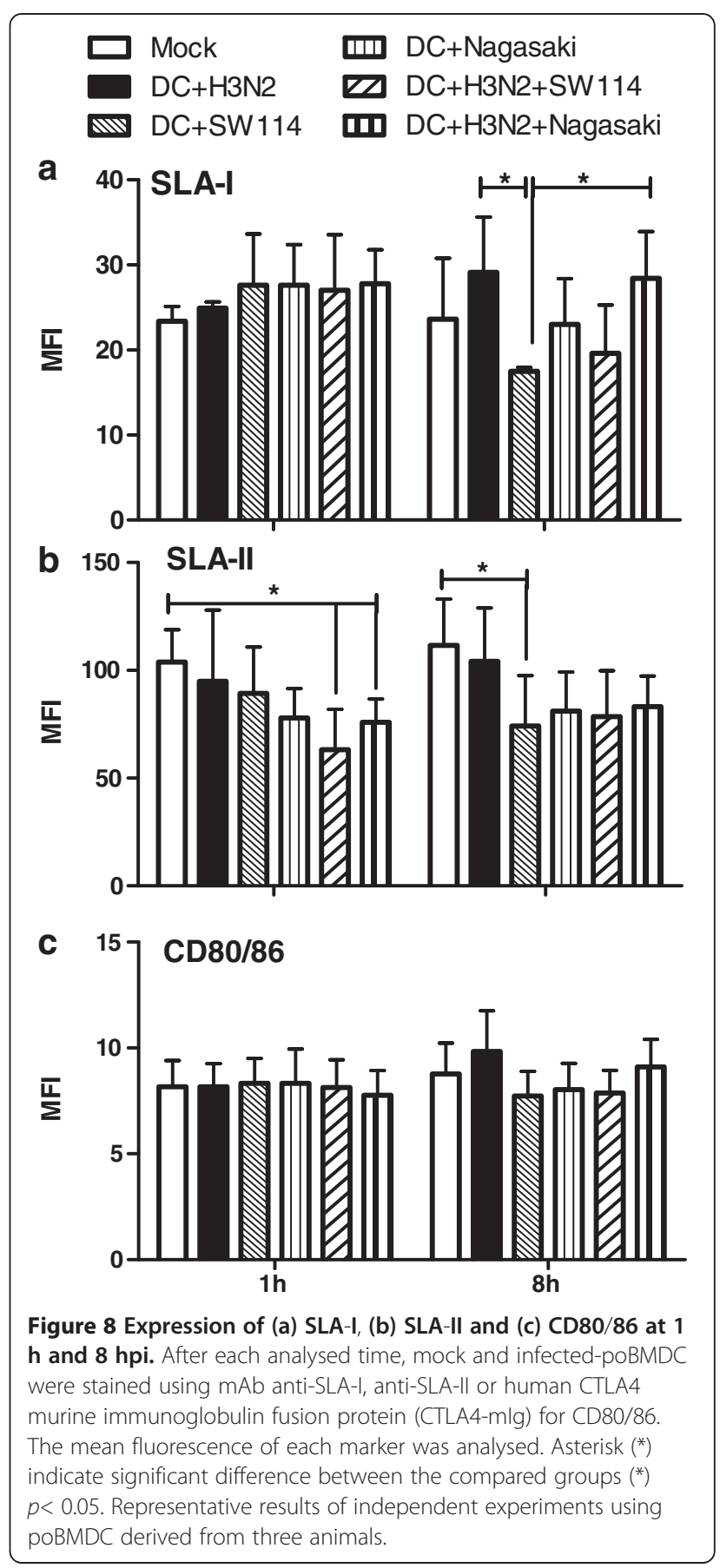

infected cells $(p=0.09)$ and IL-12 in cells infected with any $H$. parasuis strains $(p=0.10)$ (Figure 10).

\section{Discussion}

In the present study, the immune response generated by porcine DC against $H$. parasuis non-virulent serovar 3 (SW114) or virulent serovar 5 (Nagasaki) alone or after a previous infection with H3N2 SwIV was evaluated. The goals in this study were the following: (i) to establish an in vitro model to study the interaction of virulent 




and non-virulent $H$. parasuis strains with DC that could give us some insight into the virulence associated with the immune response; (ii) to analyse whether SwIV infection could alter those responses.

Dendritic cells are competent antigen-presenting cells responsible for activation of naive $\mathrm{T}$ cells and generation of primary T-cell responses [31]. DC constitute the bridge between the innate and adaptive immune response [17]. The sentinel functions and the availability of DC beneath the epithelium of respiratory organs make them a suitable target for respiratory pathogens, such as SwIV or $H$. parasuis in pigs. Extensive studies on DC have been done in mice and humans and although the knowledge on swine immunology has been developing quickly in recent years, studies to highlight the interaction of pathogens with the porcine immune system are scarce. A recent study evaluated the ability of Streptococcus suis to interact with swine DC. Thus, 


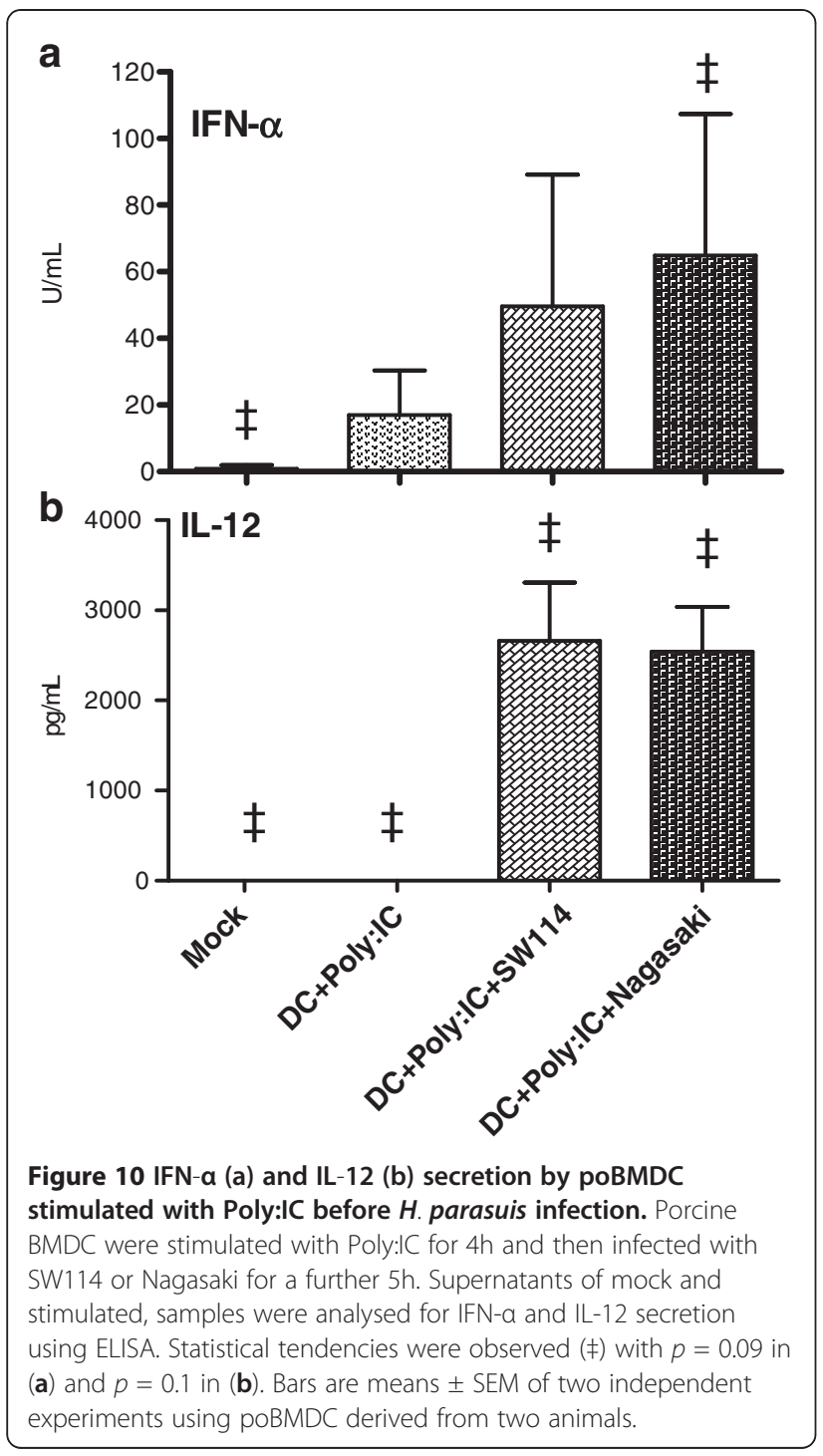

S. suis capsular polysaccharide (CPS) was shown to interfere with DC phagocytosis and to be mainly responsible for DC activation, addressing the role of S. suis CPS as a critical virulence factor [32]. In a previous study, we have shown that phagocytosis resistance was a virulence mechanism of $H$. parasuis, on porcine alveolar macrophages (PAM). Although the Nagasaki strain entered the cells, it showed negligible association with PAM [8].

In the present study, we describe marked differences in the interaction of a virulent and a non-virulent strain of $H$. parasuis with porcine DC. Firstly, SW114 was rapidly internalised by poBMDC compared to Nagasaki and this ability was not affected by a previous infection with a H3N2 SwIV. The lower level of interaction of Nagasaki with poBMDC, as it was also observed in alveolar macrophages [8], could be a general evasion strategy from the immune system. On the contrary to $H$. ducreyi which persists in DC without affecting the eukaryotic cell viability [33], Nagasaki was killed once internalized in poBMDC. Although Nagasaki was internalised in lower numbers, it induced more cellular lesions when compared to SW114, indicating that virulence factors could be acting at this level. Although cell death after $H$. parasuis infection evaluated by the number of apoptotic and necrotic cells did not change regardless of single or co-infected experiments (data not shown), it seems that one strategy of the Nagasaki strain in interacting with swine DC may be to alter cell morphology to a certain extent without inducing increased cell death.

Antigen presentation, activation of co-stimulatory markers and signalling through released cytokines are three key points in triggering an effective immune response by APC. The reduction in SLA-II observed in H3N2 SwIV plus SW114 or Nagasaki-infected cells might be due to a reduction of an accessible surface membrane since SW114 was attached in large numbers at 1 and 8 hpi. However, after $8 \mathrm{~h}$ when the interaction of both bacterial strains with DC was similar, SLA-I expression decreased in H3N2 SwIV plus SW114-infected cells while increased in H3N2 SwIV plus Nagasaki infected cells. These differences in interaction of both pathogens with poBMDC might suggest that they interfere in a different way with the transport and/or recirculation of MHC I and II molecules. For example, it has been reported that Helicobacter pylori infect murine DC and as a consequence, MHC-II is retained within the $H$. pylori vacuoles and the export of MHC-II molecules to the cell surface is blocked [34].

The activation of APC is conditioned by the local environment in which they are primed, and this influences the way in which they control T helper type $1 /$ type 2 (Th1/Th2) [35] or Th17 [36] cell development. In addition, adaptive immune response to micro-organisms is often characterised by the polarisation of the cytokine response. Generally speaking, type I cytokines are known to suppress type II responses and vice versa. Pathogens that strongly polarise the immune response may modify the type I and type II cytokine balance and/or effectors and consequently the local environment in which immunity to a concurrent micro-organism develops. In our system, swine DC infected with either of the $H$. parasuis strains tested showed a predominant inflammatory pattern of cytokines with high levels of IL-1 $\beta$, IL-8, IL-6, IL-18 and TNF- $\alpha$. Previously, Bouchet el al., reported that $H$. parasuis serotype 4 of moderate virulence, induced IL-8 and IL-6 secretion in higher levels compared to serotype 5 (high virulence) in newborn pig tracheal cells [37] while the same authors also reported that field strains of $H$. parasuis serotypes 4 and 5 induced similar levels of IL- 8 and IL-6 [38]. The data presented here indicate that there is no difference in the capacity of SW114 (serovar 3, non-virulent) or Nagasaki 
(serovar 5, virulent) to induce IL-1 $\beta$, IL-8, IL-6, IL-18, IL-10, IFN- $\alpha$ and TNF- $\alpha$ in porcine DC. Different cell types used in these studies may account for the abovementioned apparent discrepancies.

There were significant differences regarding secretion of IL-12, the non-virulent strain being a higher inducer. IL-12 is a cytokine which links both innate and adaptive immunity systems playing a critical role in inducing Th1 responses, which in turn leads to the production of a number of cytotoxic cytokines, as well as interferongamma (IFN- $\gamma$ ) by $\mathrm{T}$ cells [39]. Therefore, differential secretion of IL-12 might be considered a candidate of virulence in terms of immune responses to $H$. parasuis. Further studies will elucidate whether this will be the case in pigs. Interestingly, when SwIV co-infection took place with Nagasaki, IL-12 secretion increased to levels comparable to cells infected with non-virulent SW114, suggesting that a change in IL-12 pattern was accomplished. IFN- $\alpha$ secretion may be due to viral PAMP through TLR3 or through bacterial PAMP due to TLR4. Nagasaki and SW114 strains differ in the nature of their lipooligosacharide (LOS) [40] and capsule production [8], nevertheless, IFN- $\alpha$ secretion was similar when a single bacterial infection took place. However, these structural differences may account for the different cytokine pattern in the co-infection experiment as well as acting as a positive feedback loop for interferon upon influenza infection. In mice, Nakamura et al. reported that co-infection with influenza virus and Streptococcus pneumoniae leads to synergistic stimulation of type I IFN [41], which might also be the case in the experiments presented in this work.

Recently also in mice, Negishi et al. demonstrated a modulated antibacterial $\mathrm{T}$ cell response as a result of cross-interference of RLR and TLR signalling pathways [42]. The authors demonstrated that TLR activation through IRF5 (bacterial infection) induced high levels of IL-12 and low levels of IFN-I whereas RLR activation through IRF3 (viral infection) induced high levels of IFN-I and low levels of IL-12. These pathways of activation could also apply in the data presented here, as SW114 was a high IL-12 and low IFN- $\alpha$ inducer and SwIV a low IL-12 and high IFN- $\alpha$ inducer in infected DC, as shown in Figure 9. Negishi et al. also reported that in the case of bacterial-virus co-infection, IRF3 is able to suppress IL-12. However, this was not the case in the experiments presented here, where in the coinfection or Poly:IC stimulation, IL-12 was not only inhibited but induced by the virulent Nagasaki strain. Differences in animal species and the degree of pathogen virulence used in these studies may account for the above-mentioned apparent discrepancies.

Overall, the results presented in this work show that in vitro DC studies may help to understand the complex relationship of virulent and non-virulent bacteria and the intimate relation among different pathogens in coinfections. These in vitro analyses allowed us to investigate new avenues for the stimulation of the immune system for better response to pathogens. In conclusion, we report for the first time immunological differences among virulent versus non-virulent $H$. parasuis strains in their interaction with DC and their modulation by SwIV co-infection.

\section{Additional files}

\begin{abstract}
Additional file 1: Figure S1. H3N2 SWIV and H. parasuis SW114 or Nagasaki co-infected-poBMDC at (a) $1 \mathrm{~h}$ and (b) 8 hpi. Porcine BMDC were infected and stained using anti-SW14 or anti-Nagasaki rabbit serum $1 \mathrm{~h}$ at $4^{\circ} \mathrm{C}$, and then with the anti-rabbit IgG-FITC antibody. Mock (grey histograms), SW114 (dotted line), Nagasaki (continuous line). Representative results of two independent experiments using poBMDC were derived from two animals.

Additional file 2: Figure S2. Fluorescence images of co-infectedpoBMDCs with H3N2 SwIV and SW114 or Nagasaki at 8 hpi. Porcine BMDC were infected and stained using (a) anti-SW14 or (b) anti-Nagasaki rabbit serum, and then with the anti-rabbit IgG-Dye Light 549, and anti-mouse NP HB65 ATCC antibody followed by an anti-mouse lgG-FITC. Therefore, nuclei were stained with DAPI (blue). SW114 or Nagasaki (red) and SwIV nucleoprotein (NP: green) Bar $=25 \mu \mathrm{m}$. Representative results of two independent experiments using poBMDC were derived from two animals.

Additional file 3: Figure S3. TEM of poBMDC co-infected with H3N2 SWIV and SW114 at 8h. Porcine BMDC showed many vesicles (ves) containing SW114 $(a, b, c)$. Some vesicles had more than one bacteria (d, e). SW114 was found inside vesicles at different levels of degradation (asterisk, e, f, g). Also virus-like-particles (VLP) were observed (h, i). Bars: $\mathrm{a}=2 \mu \mathrm{m} ; \mathrm{b}-\mathrm{g}=200 \mathrm{~nm} ; \mathrm{h}=100 \mathrm{~nm}$ and $\mathrm{i}=50 \mathrm{~nm}$.

Additional file 4: Figure S4. TEM of poBMDC co-infected with $\mathrm{H} 3 \mathrm{~N} 2$ SwIV and Nagasaki at 8h. Porcine BMDC were infected with SwIV followed by Nagasaki. At 8 hpi, poBMDC showed several vesicles (ves) (a-e). Few cells showed drastic cell damage (b). Some vesicles contained more than one bacterium $(\mathrm{d}, \mathrm{g})$. The Golgi of Nagasaki-infected poBMDC was dilated $(f, h)$. Different levels of Nagasaki degradation were observed (black arrows) (h). The Golgi of Nagasaki-infected poBMDC was enlarged (i). Bars: $a-c, g=2 \mu m ; d, f, i=500 \mathrm{~nm}, e=1 \mu \mathrm{m}$ and $\mathrm{h}=200 \mathrm{~nm}$.
\end{abstract}

\section{Competing interests}

Sources of financial support have been acknowledged and the authors declare that they have no competing interest.

\section{Authors' contributions}

MM, VA, and TM designed the study, analysed and interpreted data. TM performed research and wrote the manuscript. CRC and ASC performed and analysed TEM data. JD critically reviewed the manuscript and contributed important intellectual output. LF performed the statistical analysis. MB sequenced the H3N2 SwIV. MCH performed intracellular survival assay. All authors contributed to editing of the manuscript and all authors read and approved the final manuscript.

\section{Acknowledgements}

This work was partly funded by the following Projects: CSD 2006-00007, AGL2009-12945-C02-01, AGL2010-22200-C02-01 and AGL2010-15232 by the Spanish Government. PhD studies of Mrs. Tufária Mussá are supported by a doctoral grant from the Spanish Agency of International Cooperation and Development (AECID) while PhD studies of Mrs. Mar Costa-Hurtado and Mr. Massimiliano Baratelli are supported by a doctoral grant from the Spanish Ministry of Science and Innovation (MICINN). Authors also thank Dr Francesc E. Borrás and Dr Daniel Benitez-Ribas from the DC.CAT group (the Catalan group for DCs studies) and Dr Llilianne Ganges for their comments and 
suggestion in this work. Authors thank Dr Kevin Dalton for editing the English language in the manuscript and Dr Maria Ballester, Núria Galofré and Núria Aloy for technical support.

\section{Author details}

Centre de Recerca en Sanitat Animal (CReSA), UAB-IRTA, Campus de la Universitat Autònoma de Barcelona (UAB), 08193 Bellaterra, Barcelona, Spain ${ }^{2}$ Cátedra de Patología, Facultad de Ciencias Veterinarias, Universidad Central de Venezuela, Maracay, Venezuela. ${ }^{3}$ Servei de Microscopia, Facultat de Biociències, Campus UAB, 08193 Bellaterra, Barcelona, Spain. ${ }^{4}$ Universitat de Lleida, Lleida, Spain. ${ }^{5}$ Dpto. de Biotecnología, INIA, Madrid, Spain. ${ }^{6}$ Institut de Recerca i Tecnologia Agroalimentaria (IRTA), Barcelona, Spain.

Received: 2 August 2012 Accepted: 31 October 2012

Published: 16 November 2012

\section{References}

1. Biberstein $E L$, White DC: A proposal for the establishment of two new Haemophilus species. J Med Microbiol 1969, 2:75-78.

2. Amano H, Shibata M, Kajio N, Morozumi T: Pathologic observations of pigs intranasally inoculated with serovar 1,4 and 5 of Haemophilus parasuis using immunoperoxidase method. J Vet Med Sci 1994, 56:639-644.

3. Aragon V, Segales J, Oliveira S: Glässer's Disease. In Disease of Swine. $10^{\text {th }}$ edition. Edited by Zimmerman JJ, Karriker LA, Schwartz KJ, Stevenson GW: Wiley-Blackwell; 2012:760-769.

4. Oliveira S, Galina L, Pijoan C: Development of a PCR test to diagnose Haemophilus parasuis infections. J Vet Diagn Invest 2001, 13:495-501.

5. Kielstein P, Rapp-Gabrielson VJ: Designation of 15 serovars of Haemophilus parasuis on the basis of immunodiffusion using heat-stable antigen extracts. J Clin Microbiol 1992, 30:862-865.

6. Olvera A, Segales J, Aragon V: Update on the diagnosis of Haemophilus parasuis infection in pigs and novel genotyping methods. Vet J 2007 , 174:522-529.

7. Olvera A, Calsamiglia M, Aragon V: Genotypic diversity of Haemophilus parasuis field strains. Appl Environ Microbiol 2006, 72:3984-3992.

8. Olvera A, Ballester M, Nofrarias M, Sibila M, Aragon V: Differences in phagocytosis susceptibility in Haemophilus parasuis strains. Vet Res 2009, 40:24

9. Cerda-Cuellar M, Aragon V: Serum-resistance in Haemophilus parasuis is associated with systemic disease in swine. Vet J 2008, 175:384-389.

10. Aragon V, Bouchet B, Gottschalk M: Invasion of endothelial cells by systemic and nasal strains of Haemophilus parasuis. Vet J 2010, 186:264-267.

11. Vanier G, Szczotka A, Friedl P, Lacouture S, Jacques M, Gottschalk M: Haemophilus parasuis invades porcine brain microvascular endothelial cells. Microbiology 2006, 152:135-142

12. Frandoloso R, Martinez-Martinez S, Gutierrez-Martin CB, Rodriguez-Ferri EF: Haemophilus parasuis serovar 5 Nagasaki strain adheres and invades PK-15 cells. Vet Microbiol 2012, 154:347-352.

13. Heinen P: Swine influenza: a zoonosis. Ed: V S Tomorrow; 2002

14. Horimoto T, Kawaoka Y: Pandemic threat posed by avian influenza A viruses. Clin Microbiol Rev 2001, 14:129-149.

15. Lipatov AS, Govorkova EA, Webby RJ, Ozaki H, Peiris M, Guan Y, Poon L, Webster RG: Influenza: emergence and control. J Virol 2004, 78:8951-8959.

16. Barbe F, Atanasova K, Van Reeth K: Cytokines and acute phase proteins associated with acute swine influenza infection in pigs. Vet $J 2011$ 187:48-53.

17. Steinman RM: Linking innate to adaptive immunity through dendritic cells. Novartis Found Symp 2006, 279:101-109. discussion 109-113, 216-109.

18. Liu YJ: IPC: professional type 1 interferon-producing cells and plasmacytoid dendritic cell precursors. Annu Rev Immunol 2005, 23:275-306.

19. Summerfield A, McCullough KC: The porcine dendritic cell family. Dev Comp Immunol 2009, 33:299-309.

20. Freer G, Matteucci D: Influence of dendritic cells on viral pathogenicity. PLoS Pathog 2009, 5:e1000384.

21. Fablet C, Marois C, Dorenlor V, Eono F, Eveno E, Jolly JP, Le Devendec L, Kobisch M, Madec F, Rose N: Bacterial pathogens associated with lung lesions in slaughter pigs from 125 herds. Res Vet Sci 2012, 93:627-630.

22. Simon-Grifé M, Martin-Valls GE, Vilar MJ, Busquets N, Mora-Salvatierra M, Bestebroer TM, Fouchier RA, Martin M, Mateu E, Casal J: Swine influenza virus infection dynamics in two pig farms; results of a longitudinal assessment. Vet Res 2012, 43:24

23. Olvera A, Sibila M, Calsamiglia M, Segales J, Domingo M: Comparison of porcine circovirus type 2 load in serum quantified by a real time PCR in postweaning multisystemic wasting syndrome and porcine dermatitis and nephropathy syndrome naturally affected pigs. J Virol Methods 2004, 117:75-80.

24. Sibila M, Calsamiglia M, Segales J, Blanchard P, Badiella L, Le Dimna M, Jestin A, Domingo M: Use of a polymerase chain reaction assay and an ELISA to monitor porcine circovirus type 2 infection in pigs from farms with and without postweaning multisystemic wasting syndrome. Am J Vet Res 2004, 65:88-92

25. Carrasco CP, Rigden RC, Schaffner $R$, Gerber $H$, Neuhaus $V$, Inumaru $S$, Takamatsu H, Bertoni G, McCullough KC, Summerfield A: Porcine dendritic cells generated in vitro: morphological, phenotypic and functional properties. Immunology 2001, 104:175-184.

26. Mussa T, Rodriguez-Carino C, Pujol M, Cordoba L, Busquets N, Crisci E, Dominguez J, Fraile L, Montoya M: Interaction of porcine conventional dendritic cells with swine influenza virus. Virology 2011, 420:125-134.

27. Morozumi T, Nicolet J: Some antigenic properties of Haemophilus parasuis and a proposal for serological classification. J Clin Microbiol 1986, 23:1022-1025

28. ImageJ v1.42k software. http://rsb.info.nih.gov/ij.

29. Rodriguez-Carino C, Duffy C, Sanchez-Chardi A, McNeilly F, Allan GM Segales J: Porcine circovirus type 2 morphogenesis in a clone derived from the I35 lymphoblastoid cell line. J Comp Pathol 2011, 144:91-102.

30. Kekarainen T, Montoya M, Dominguez J, Mateu E, Segales J: Porcine circovirus type 2 (PCV2) viral components immunomodulate recall antigen responses. Vet Immunol Immunopathol 2008, 124:41-49.

31. Inaba K, Metlay JP, Crowley MT, Witmer-Pack M, Steinman RM: Dendritic cells as antigen presenting cells in vivo. Int Rev Immunol 1990, 6:197-206.

32. Lecours MP, Segura M, Lachance C, Mussa T, Surprenant C, Montoya M, Gottschalk M: Characterization of porcine dendritic cell response to Streptococcus suis. Vet Res 2011, 42:72

33. Banks KE, Humphreys TL, Li W, Katz BP, Wilkes DS, Spinola SM: Haemophilus ducreyi partially activates human myeloid dendritic cells. Infect Immun 2007, 75:5678-5685.

34. Khatri M, Dwivedi V, Krakowka S, Manickam C, Ali A, Wang L, Qin Z, Renukaradhya GJ, Lee CW: Swine influenza H1N1 virus induces acute inflammatory immune responses in pig lungs: a potential animal mode for human H1N1 influenza virus. J Virol 2010, 84:11210-11218.

35. Kapsenberg ML: Dendritic-cell control of pathogen-driven T-cell polarization. Nat Rev Immunol 2003, 3:984-993.

36. Zhu J, Yamane H, Paul WE: Differentiation of effector CD4 T cell populations (*). Annu Rev Immunol 2010, 28:445-489.

37. Bouchet B, Vanier G, Jacques M, Gottschalk M: Interactions of Haemophilus parasuis and its LOS with porcine brain microvascular endothelial cells. Vet Res 2008, 39:42

38. Bouchet B, Vanier G, Jacques M, Auger E, Gottschalk M: Studies on the interactions of Haemophilus parasuis with porcine epithelial tracheal cells: limited role of LOS in apoptosis and pro-inflammatory cytokine release. Microb Pathog 2009, 46:108-113.

39. O'Garra A, Murphy KM: From IL-10 to IL-12: how pathogens and their products stimulate APCs to induce $\mathrm{T}(\mathrm{H}) 1$ development. Nat Immunol 2009, 10:929-932.

40. Martínez-Moliner V, Soler-Llorens P, Moleres J, Garmendia J, Aragon V: Distribuition of genes involved in sialic acid utilization in traisn of Haemophilus parasuis. Microbiology 2012, 158:2117-2124.

41. Nakamura S, Davis KM, Weiser JN: Synergistic stimulation of type I interferons during influenza virus coinfection promotes Streptococcus pneumoniae colonization in mice. J Clin Invest 2011, 121:3657-3665.

42. Negishi H, Yanai H, Nakajima A, Koshiba R, Atarashi K, Matsuda A, Matsuki K, Miki S, Doi T, Aderem A, Nishio J, Smale ST, Honda K, Taniguchi T: Crossinterference of RLR and TLR signaling pathways modulates antibacterial T cell responses. Nat Immunol 2012, 13:659-666.

\section{doi:10.1186/1297-9716-43-80}

Cite this article as: Mussá et al:: Differential interactions of virulent and non-virulent $H$. parasuis strains with naïve or swine influenza virus preinfected dendritic cells. Veterinary Research 2012 43:80. 